\title{
Serrated Nodule
}

National Cancer Institute

\section{Source}

National Cancer Institute. Serrated Nodule. NCI Thesaurus. Code C157671.

A jagged, ragged, saw-tooth appearance in which individual extensions extend less than 3 $\mathrm{mm}$ from adjacent margins. Do NOT include subtle tenting if only observed at the site of external septal stretching. 